\title{
Clinical Evaluation of the Tonsils for Malignancy: The Necessity of Histopathological Examination
}

\author{
Mohammad Hossein Taziki (PhD) \\ Department of Otolaryngology, \\ Golestan University of Medical \\ Sciences, Gorgan, Iran \\ Ramin Azarhoush (PhD) \\ Department of Pathology, Golestan \\ University of Medical Sciences, \\ Gorgan, Iran \\ Mohammad Mahdi Taziki \\ Medical student, Mazandaran \\ University of Medical Sciences, \\ Mazandaran, Iran \\ Corresponding author: Mohammad \\ Hossein Taziki \\ Tel: +989111719461 \\ Email: hoseinta@yahoo.com \\ Address: Department of \\ Otolaryngology, Golestan University \\ of Medical Sciences, Gorgan, Iran \\ Received : 14 Mar 2017 \\ Revised: 01 Feb 2018 \\ Accepted: 12 Feb 2018
}

ABSTRACT

Background and Objectives: Tonsils are lymphoid tissues that can be affected in various diseases. In some cases, it is necessary to remove tonsils through surgery. Although the diseases are often diagnosed by history taking and physical examination that proceeds with surgery, histologic examination is necessary for confirmed diagnosis of malignancy. Considering the low prevalence of tonsil cancer, this study was performed to clinically examine tonsils for malignancies and evaluate the necessity of histopathological examination.

Methods: This retrospective study was conducted on 2,232 patients (aged 2-80 years) who had undergone tonsillectomy for various reasons in the city of Gorgan from 2001 to 2012. Medical history was obtained and physical examination was carried out before surgery. All the samples were sent to the laboratory for histopathological examination. Finally, the collected data was analyzed.

Results: 0nly one case of lymphoma was found among the 2,232 patients investigated in this study. This 80 -year-old woman with preoperative cervical lymphadenopathy and unilateral tonsillar enlargement went under tonsillectomy for confirmed diagnosis.

Conclusion: Considering the high frequency of tonsillectomy and the low possibility of malignancy, and the fact that malignancy is often seen in individuals with obvious clinical presentations such as in our case, it is recommended to limit referral of specimens for histological examination to highly suspicious cases through more rational decision-making and summarization of other findings.

Keywords: Hypertrophy, Malignancy, Lymphoma Pathology, Tonsillectomy. 


\section{INTRODUCTION}

Tonsils are part of Waldeyer's ring of lymphoid tissue and play a major role in protecting the body against respiratory infections, especially during childhood (1). Tonsillectomy may be required for multiple reasons. Prevalence of tonsillectomy is very high with annual rates ranging between one and three million surgeries in America (2). It is still considered as the most common surgery in the field of otolaryngology. One of the absolute indications for tonsillectomy is acute or recurrent attacks of tonsillitis in which the patient experiences fever, chills, frequent sore throat (pharyngitis), fatigue and generalized weakness (4). Peritonsillar abscess often has noisy symptoms that urge the patient to visit a doctor, and may eventually lead to surgery. Diphtheria carriers and enlargement of tonsils that can cause respiratory problems are among other symptoms of peritonsillar abscess. Diagnosis is usually made based on clinical findings and physical examination with no need for a positive biopsy for surgery.

Suspected malignancy is considered as another surgical indication. This means that the presence of asymmetrically enlarged tonsils or clinical evidence indicates the need for tonsillectomy, and biopsy should be sent to pathology laboratory for definitive diagnosis (5). Given the high cost of sampling and laboratory testing, the necessity of sending all samples to the laboratory has been debated in several studies (5-8). Therefore, this study was performed to clinically examine tonsils for malignancies and evaluate the necessity of histopathological examination.

\section{MATERIAL AND METHODS}

This retrospective study was conducted on2,232 patients who had undergone tonsillectomy for various reasons in the city of
Gorgan (Iran), 2001-12. According to routine procedures, the samples were taken and sent to the laboratory for histopathological examination.

After obtaining medical history and performing physical examination, the indication for surgery were evaluated. After surgery, patients were monitored and eventually discharged from the hospital. The physicians carried out postoperative follow up and care, and patients received advice for homecare.

Many patients did not revisit for the biopsy results, but according to the current procedure, all pathological results were observed by a physician to avoid overlooking the conditions. In case of suspected malignancy, careful attention was paid to the medical history and physical examination. Ultimately, pathology findings for the 10-year period were reviewed and analyzed.

\section{RESULTS}

Overall, 2,232 pathology samples were studied in a 10-year period. Age of patients ranged between 2 and 80 years. Surgical indications included hearing problems, difficulty breathing or airway obstruction, frequent sore throat, peritonsillar abscess and a case of suspected malignancy. This case was an 80-year-old woman with cervical lymphadenopathy and unilateral tonsillar enlargement whom underwent surgery for establishing a definitive diagnosis. In the histological view of tonsil tissue, diffuse large malignant lymphocytes with multiple mitosis were observed.

The patient was diagnosed with diffuse large cell immunoblastic lymphoma (high-grade).

The patient was then referred to oncology ward for treatment.

Table 1- Age distribution of patients undergoing tonsillectomy

\begin{tabular}{lllllll}
\hline Age (years) & $0-5$ & $5-10$ & $10-15$ & $15-20$ & $20-25$ & 25 and older \\
\hline Number & 428 & 135 & 415 & 89 & 47 & 118 \\
Percentage & $19.2 \%$ & $50.8 \%$ & $18.6 \%$ & $4 \%$ & $2.1 \%$ & $5.3 \%$ \\
\hline
\end{tabular}

Table 2- Frequency distribution of patients undergoing tonsillectomy based on gender

\begin{tabular}{ccc}
\hline & Number & Percentage \\
\hline Male & 1166 & $52.3 \%$ \\
Female & 1066 & $47.7 \%$ \\
Total & 2232 & 100 \\
\hline
\end{tabular}




\section{DISCUSSION}

The tonsils play an important protective role during childhood. However, they can be affected by various diseases that may require surgery. These cases are divided into three categories according to some resources (9). Upper respiratory obstruction and acute infections are among conditions that do not require pre-surgical biopsy, and pathological findings do not affect the treatment procedure. The only definite indication for surgery that requires histological examination is the case of malignancy. In addition, determination of tissue type is important for establishing the course of treatment. Squamous cell carcinoma and lymphoma are the two most common malignant tumors of the tonsils, and despite the risk of morbidity, surgery plays a key role in treatment of squamous cell carcinoma cases (10).

Previous studies have demonstrated that the age of developing oral cavity and oropharyngeal cancers is rising (11). Moreover, the prevalence of tonsil cancer has increased from 0.6 to 1.45 per 100,000 in the southeast of England, which is even more significant in men aged 40-59 years (12). In case of oropharyngeal cancer, the incidence of tonsillar carcinoma and base of tongue cancer has been increasing (13). These cases could be diagnosed clinically to a great extent. In study of Rothy et al., among three patients aged 5768 years with tonsillar lymphoma, one had limited unilateral enlargement of the tonsils, another had hepatic, spleen and mediastinal involvement, and the third case was diagnosed with undifferentiated carcinoma. All these subjects were suspected with malignancy preoperatively and had undergone surgery (14).

In another study, lymphoma diagnosis was confirmed after surgery in a 57-year-old patient with bilateral tonsil hypertrophy, irresponsive to conventional therapy and strong preoperative doubts regarding cancer surgery (15). Doler reported six patients with unilateral tonsillar enlargement with suspicion of malignancy whom underwent surgery (16). However, it is not clear whether samples from all patients should be referred for histopathological examination or not. Starrd in 1939 and Yarington in 1967 recommended that all tissue samples should be evaluated, while Welbel claimed that routine examinations are unnecessary (17). According to the routine procedures in our center, all obtained samples from patients undergoing tonsillectomy should be sent to the laboratory for pathological examination.

In the study of Dobarand Bonilla in 1996, only one case of cancer was reported among 2012 samples from tonsillectomy surgeries (3). In addition, no malignancy was found in studies of Strong et al. (18) on 1583 patients and Ounis et al. (19) on 2099 patients aged less than 18 years. In 2003, Williams and Brown reported only three cases of malignancy among 4070 patients under 21 years of age (20). Garavello et al. found four malignancy cases among 1123 patients under 16 years of age (21). No case of malignancy was reported in the study of Erdag et al. in 2005 on 2743 patients aged less than 18 years (22). Verma et al. in 2009 also reported no malignancy in 2062 tested samples (23). Study of Sturm on 7337 samples from patients aged less than 19 years reported only two cases of malignancy (24). In our study on 2,232 patients aged 2-80 years, only one case of cancer was found. In this case, clinical symptoms such as the neck mass and unilateral tonsillar enlargement were evident, and diagnosis of lymphoma was confirmed after surgery.

Considering the results of the present study and previous studies, cancer is expected only in cases with strong suspicion of malignancy before surgery, and if the medical history taking and physical examination are carried out with sufficient accuracy, cancer can be predicted before surgery.

\section{CONCLUSION}

Given the high cost of pathological examination and the necessity for adherence to health economic policies (i.e. priority-based allocation of funds), continuous studies and principled decision-making may help reduce the number of unnecessary biopsies and pathological examinations.

\section{ACKNOWLEDGEMENTS}

The authors would like to thank all operating room and laboratory personnel, and physicians of teaching hospitals in the city of Gorgan for their cooperation.

\section{CONFLICT OF INTEREST}

All contributing authors declare no conflict of interest. 


\section{REFERENCES}

1. Conley SF, Ellison MD. Avoidance of primary posttonsillectomy hemorrhage in a teaching program Arch Otolaryngol Head Neck Surg. 1999; 125(3): 330-333.

2. ALFRED KORNBLUT . MD, ALAND KORNBLUT 'Tonsillectomy and Adenoidectomy'. Michael M paparella . Donald A. Shumrick otolaryngology head and neck surgery 3th edd. Saunders company volum III 1991 PP. $2189-2198$.

3. Dohar JE, Bonilla JA. Processing of adenoid and tonsil specimens in children. a national survey of standard practices and a five-year review of the experience at the childrens Hospital of Pittsburgh. Otolaryngol Head Neck Surg. 1996; 115(1): 94-7.

4. Homer JJ, Williams BT, Semple P, Swanepoel A, Knight LC.

Tonsillectomy by guillotine is less painful than by dissection. Int J Pediart Otorhinolaryngol. 2000; 52(1): 25-29.

5. Adams DA, Cinnamond MJ. Scott Browns otolaryngology. $6^{\text {th }}$ ed. Otolaryngol Head Neck Surgh. 1996; 115: 94-97.

6. Collison PJ, Metter B. Factors associated with post tonsillectomy hemorrhage. Ear Nose and Throat Journal. 2000; 79(8): 640-2, 644, 646 passim.

7. Windfuhr JP, Chen YS. Incidance of posttonsillectomy hemorrhage in children and adults. Ear Nose \& Throat Jounal. 2002; 81(9): 626-8, 630, 632 passim.

8. Bailey BJ. Tonsils and adenoid. Snapshots from the Laryngoscope scrapbook. Layngoscope. 1997; 107(3): 301-306.

9. Peyton Shirley. W 'Audie L. Woolley’ Briany Wiatuk "Pharyngitis and adenotonsillar disease" Paulw. Flint, Bruce. H Houghey' Valerie , Lund etall. Cumming's Otolarangology Head \& neck surgery Fifthedition Bosbx 2010. PP 2783-2801.

10. Jaber JJ. Moreira J. Canar WJ. Bier-Laning CM. A 25- Year analysis of veterans treated for tonsillar squamous cell carcinoma. Arch Otolaryngol Head Neck surg. 2009 Nov. 135(11): 1147-53. doi: 10.1001/archoto.2009.164.

11. Reddy VM, Cundall- Curry D, Bridger MYY. Trends in the incidence rates of tonsil and base of tongus cancer in England, 1985- 2006. Ann R coll surg Engl. 2010; 92(8): 655-9. doi: 10.1308/003588410X12699663904871.

12. Olaleye O, Moorthy R, Lyne O, Black M, Mitchell $\mathrm{D}$, Wiseberg J. A 20-year retrospective study of tonsil cancer incidence and survical trends in south East England: 1987-2006. Clin Otolaryngol. 2011; 36(4): 325-35. doi: 10.1111/j.1749-4486.2011.02361.x.
13. Gourin CG. Fnck KD. National trends in oropharyngeal cancer surgery and the effect of surgeon and hospital volume on short-term outcomes and cost of care. Laryngoscope. 2012; 122(3): 543-51. Doi: 10. 1002/lary:22447.

14. Roth Y, Spilberg D, Douer D, Nass D, Leventon G. [Tonsillar lymphoma]. Harefuah.1990; 118(8): 449-52.

15. Khan SU, Kenefick C, O'Leary G, Lucey JJ. NonHodgkin lymphoma presenting as bilateral tonsillar hypertrophy: Case report.2010; 89(4): E4-5.

16. Dolev y, Daniel SJ. The presence of unilateral tonsillar enlargement in patients diagnosed with palatine tonsil lumphoma: experience at a tertiary care pediatric hospital. Int J Pediatr Otorhinolaryngol. 2008; 72(1): 912.

17. Weibel E. Pathological findings of clinical value in tonsils and adenoids. Acta OtoLaryngol 1965, 60(1-6): 331-338.

18. Strong EB, Rubinstain B, Senders CW. Pathologic analysis of routine and tonsillectomy specimen. Otolarygol Head Neck Surg. 2001;125(5): 473-477.

19. Younis RT, Hesse SV, Anand VK. Evaluation of the utility and cost-effectiveness of obtaining histopathologic diagnosis on all routine tonsillectomy specimens. Laryngoscope 2001; 111(12): 2166-2169.

20. Williams MD, Brown HM. The adequacy of gross pathological examination of routine tonsils and adenoids in patients 21 years old and younger. Hum Pathol. 2003; 34(10): 1053-1057.

21. Garavello W, Romagnoli M, Sordo L, Spreafico R, Gaini RM. Incidence of unexpected malignancies in routine tonsillectomy specimens in children. Laryngoscope. 2004; 114(6): 1103-1105.

22. Erdag TK, Ecevite MC, Guneri EA, et al. Pathologic evaluation of routine tonsillectomy and adenoidectomy specimens in the pediatric population is it really necessary? Int J Pediatr Otohinolaryngol. 2005; 69(10): 1321-1325.

23. Verma SP, Stoddard T, Gonzalez-Gomez I, Koempel JA. Histologic analysis of pediatric tonsil and adenoid specimens: Is it really necessary? Int J Pediatr Otorhinolaryngol.2009; 73(4):547-50. doi: 10.1016/j.ijporl.2008.11.001.

24. Sturm-O'Brien AK, Hicks JM, Giannoni CM, Sulek M, Friedman EM. Optimal utilization of histopathologic analysis of tonsil and adenoid specimens in the padiatric population Int J pediatr Otorhinolaryngol 2010; 74(2): 161-3. doi: 10.1016/j.ijporl.2009.10.028. 